\title{
SISTEM RUMAH CERDAS BERBASIS IOT DENGAN MIKROKONTROLER NODEMCU DAN APLIKASI TELEGRAM
}

\author{
Agung Pangestu*1), Ayesha Ziky Iftikhor ${ }^{2)}$, Damayanti ${ }^{3)}$, Muhammad Bakri' ${ }^{4)}$, Muhammad \\ Alfarizi $^{5)}$ \\ 1,2,4) Program Studi Teknik Komputer, Fakultas Teknik dan Ilmu Komputer, Universitas Teknokrat Indonesia \\ Jl. ZA. Pagar Alam No.9 -11, Labuhan Ratu, Bandar Lampung, Indonesia 35132 \\ ${ }^{3)}$ Program Studi Sistem Informasi, Fakultas Teknik dan Ilmu Komputer, Universitas Teknokrat Indonesia \\ Jl. ZA. Pagar Alam No.9 -11, Labuhan Ratu, Bandar Lampung, Indonesia 35132 \\ ${ }^{5)}$ Program Studi Teknologi Informasi, Fakultas Teknik dan Ilmu Komputer, Universitas Teknokrat Indonesia \\ Jl. ZA. Pagar Alam No.9 -11, Labuhan Ratu, Bandar Lampung, Indonesia 35132
}

Email: ${ }^{1}$ agungpangestu28@teknokrat.ac.id

\begin{abstract}
Electricity is a primary need for humans in carrying out their daily lives, while the current basic electricity tariff is getting higher, so it is necessary to save money so that wasteful measures can be reduced and ways to make savings are one of them by implementing a remote electrical equipment control system that uses Internet of Things (IoT) Smart Home system. This research aims to design and implement an IoT system in the form of a prototype for temperature monitoring and control of electrical equipment that is in the residential sphere using the Telegram application. The device used in designing the Smart Home IoT system is divided into several parts, namely the input, process and output sections. The input part consists of a room temperature sensor, the process part consists of the NodeMCU ESP8266 microcontroller, and the output part consists of a relay module, $L E D$ indicator, and Active Buzzer. After implementing and analyzing the test results, this system shows it can work well overall starting from the connection to Wi-Fi, communicating with the Telegram server, receiving commands, sending notifications, to reading the status of sensors and relays.
\end{abstract}

Keywords: electricity, IoT, microcontroller, NodeMCU, telegram

\section{Abstrak}

Listrik merupakan kebutuhan kebutuhan primer bagi manusia dalam menjalankan kehidupan sehari-hari, sedangkan tarif dasar listrik saat ini semakin tinggi sehingga perlu dilakukan upaya penghematan agar tindakan pemborosan dapat dikurangi dan cara untuk melakukan penghematan ini salah satunya dengan menerapkan sistem kendali peralatan listrik jarak jauh yang menggunakan sistem IoT Smart Home. Penelitian ini bertujuan untuk merancang dan mengimplementasikan sistem IoT dalam bentuk prototype untuk monitoring temperatur dan pengendalian peralatan listrik yang berada diruang lingkup perumahan menggunakan aplikasi Telegram.
Perangkat yang digunakan dalam perancangan sistem Smart Home IoT dibagi menjadi beberapa bagian yaitu bagian input, proses, dan output. Bagian input terdiri dari sensor temperatur ruangan, bagian proses terdiri dari mikrokontroler NodeMCU ESP8266, dan bagian output terdiri dari module relay, LED indikator, dan Active Buzzer. Setelah dilakukan implementasi dan analisis hasil pengujian, sistem ini menunjukkan dapat bekerja dengan baik secara keseluruhan dimulai dari koneksi ke Wi-Fi, berkomunikasi dengan server Telegram, menerima perintah, mengirim notifikasi, hingga membaca status dari sensor dan relay.

Kata Kunci: IoT, listrik, mikrokontroler, NodeMCU, telegram

\section{Pendahuluan}

Konsumsi listrik di Indonesia pada tahun 2017 mencapai 56,333.08 MW [1], dimana salah satu sektor terbanyak yang mengkonsumsi listrik tersebut adalah sektor rumah tangga. Komsumsi ini mempengaruhi cadangan energi nasional. Hingga saat ini $95 \%$ kebutuhan energi nasional masih dipenuhi dari energi fosil dan $5 \%$ yang dipenuhi energi terbarukan. Listrik merupakan kebutuhan kebutuhan primer bagi manusia dalam menjalankan kehidupan sehari-hari [2] sedangkan tarif dasar listrik saat ini semakin tinggi sehingga perlu dilakukan upaya penghematan agar tindakan pemborosan dapat dikurangi dan cara melakukan penghematan salah satunya dengan menerapkan sistem kendali [3] peralatan listrik jarak jauh yang menggunakan sistem IoT Smart Home. Kemajuan teknologi yang terjadi dapat dimanfaatkan dalam mempermudah pekerjaan manusia [4]. Fakta tersebut memicu munculnya sebuah inovasi yang memungkinkan setiap peralatan atau perangkat yang berada didalam sebuah rumah dapat dikendalikan secara jarak jauh dengan memanfaatkan teknologi internet.

Media aplikasi atau situs web khusus yang dirancang untuk menjadi media pengendali kelistrikan peralatan rumah tangga sehingga akan mengurangi tingkat komsumsi energi Listrik. IoT dapat digunakan untuk mengatasi pemborosan energi listrik yang terjadi karena 
banyaknya peralatan rumah tangga yang sering ditinggal oleh pemilik rumah dalam keadaan menyala. Pemanfaatan IoT dapat diterapkan pada sistem pengendalian kelistrikan seperti lampu, peralatan rumah tangga, dan memonitoring kondisi terkini dari rumahnya seperti temperatur ruangan hingga siaran langsung dari kamera CCTV yang dapat dilihat melalui media aplikasi desktop, mobile, dan website. Teknologi IoT juga dapat digunakan untuk mempermudah memonitoring keamanan rumah sehingga dapat mempermudah kegiatan penghuni rumah [5].

Proses yang dibutuhkan untuk mengubah sistem kelistrikan rumah konvensional menjadi sistem smart home (rumah cerdas) berbasis IoT sehingga dapat mempermudah aktivitas manusia [6]. Perangkat yang dibutuhkan agar dapat membuat peralatan rumah tangga terkoneksi dengan Wi-Fi untuk mendapatkan koneksi Internet. Namun masih sering nya terjadi pemadaman listrik dibeberapa wilayah di Indonesia. Saat ini banyak module yang dapat digunakan untuk membuat peralatan rumah tangga terkoneksi dengan akses internet melalui Wi-Fi, modul misalnya mikrokontroler NodeMCU ESP8266 yang mampu beroperasi menggunakan tegangan 5 volt yang dihasilkan 1 (satu) buah baterai 18650 .

Beberapa penelitian terkait diantaranya: sistem rumah cerdas untuk memonitoring kelembaban suhu di kamar [7] rumah cerdas dalam mengatur kondisi lampu, garasi, lemari es, pompa air, pintu gerbang yang terhubung dengan webcam [8][9]. Pada penelitian terdahulu sebagian belum terintegrasi dengan perancangan menggunakan aplikasi telegram, sehingga untuk mempermudah penggunaan sistem smart home dan meminimalisir biaya pembuatan sistem, maka penelitian ini bertujuan untuk merancang dan mengimplementasikan sistem IoT dalam bentuk prototype untuk monitoring temperatur dan pengendalian peralatan listrik yang berada diruang lingkup perumahan menggunakan aplikasi telegram. Sistem yang dirancang dengan memanfaatkan API aplikasi telegram yang disisipkan ke sketch untuk diupload ke Mikrokontroler NodeMCU ESP8266 agar dapat dikendalikan dengan menggunakan aplikasi chatting telegram yang dapat diunduh secara gratis baik melalui komputer, maupun melalui smartphone berbasis Android atau IOS.

\section{Metode}

Penelitian ini menggunakan metode IoT yang merupakan arsitektur terdiri dari hardware khusus, sistem software, Web API, protocol yang bersama membuat lingkungan yang mulus dimana perangkat pintar dapat terkoneksi ke internet semisal data sensor dapat diakses dan sistem control dapat digerakkan melalui internet. Perangkat dapat terhubung ke internet menggunakan berbagai cara seperti Ethernet, Wi-Fi, Bluetooth, dan sebagainya. Perangkat mungkin juga tidak terkonekesi dengan internet secara langsung, namun dikelompokkan dalam kluster (sebagai contoh jaringan sensor) dan terhubung ke base station (terhubung ke internet). Penelitian ini menggunakan perangkat pendukung yang ditunjukkan pada Tabel 1:
Tabel 1. Kebutuhan perangkat

\begin{tabular}{clcc}
\hline No. & Nama Komponen & Jumlah & Satuan \\
\hline 1 & Mikrokontroler & 1 & Unit \\
& $\begin{array}{l}\text { NodeMCU } \\
\text { ESP8266 }\end{array}$ & & \\
2 & Module Relay 4- & 1 & Unit \\
3 & Channel & 1 & Unit \\
4 & DHT11 Sensor & 1 & Unit \\
5 & Active Buzzer & 1 & Unit \\
6 & Module DC Step Up & 1 & Unit \\
7 & Baterai 18650 3.7 V & 1 & Unit \\
8 & Charger 18650 & 4 & Unit \\
9 & LED & 5 & Unit \\
10 & Kabel Jumper & 1 & Unit \\
11 & PCB Breadboard & 1 & Unit \\
& Kabel USB & & \\
\hline
\end{tabular}

a. Mikrokontroler NodeMCU ESP8266

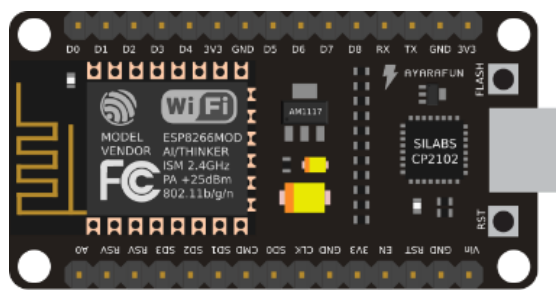

Gambar 1. Interface NodeMCU ESP 8266

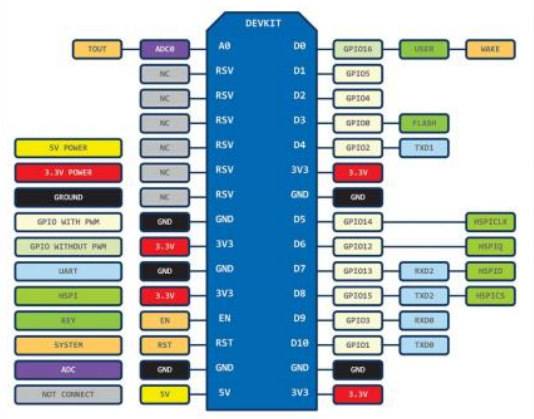

Gambar 2. Skematik pin NodeMCU ESP8266

b. DHT11 Sensor

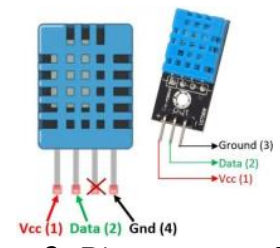

Gambar 3. Pinout sensor DHT11 
c. Module Relay 4-Channel

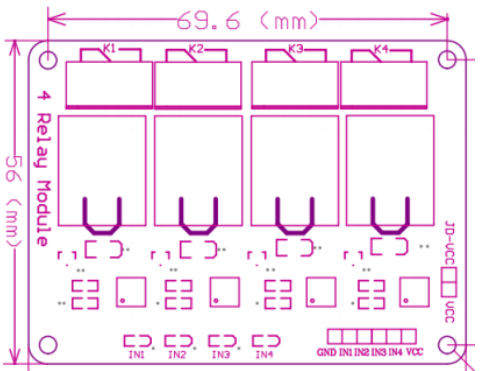

Gambar 4. Pinout module Relay 4 Channel

d. Active Buzzer

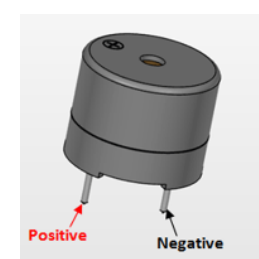

Gambar 5. Pinout Active Buzzer

e. Kabel USB

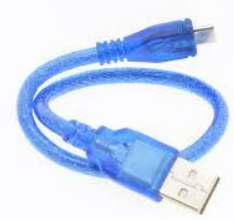

Gambar 6. Kabel USB to NodeMCU

f. Baterai $186503.7 \mathrm{~V}$

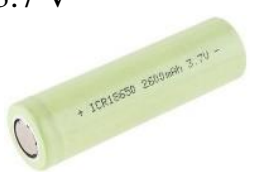

Gambar 7. Baterai 18650 2600mAh

g. Charger 18650

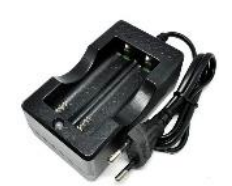

Gambar 8. Charger baterai 18650

h. LED
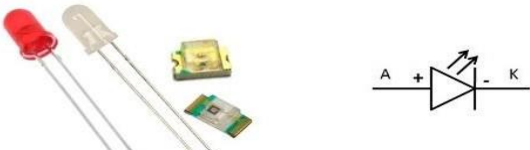

Gambar 9. Bentuk dan pinout LED

i. Kabel Jumper

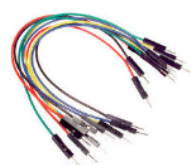

Gambar 10. Kabel jumper j. PCB Breadboard

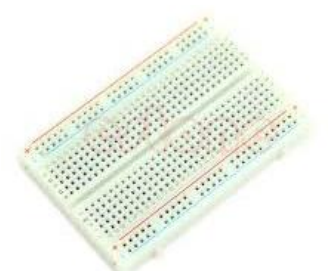

Gambar 11. Breadboard

k. Module DC Step Up

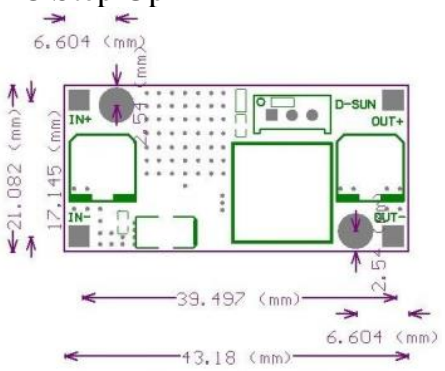

Gambar 12. Pinout DC Step Up Module

Tabel 2. Fungsi Perintah pada Telegram

\begin{tabular}{ll}
\hline \multicolumn{1}{c}{ Perintah } & \multicolumn{1}{c}{ Fungsi } \\
\hline /newbot & Membuat bot baru \\
/mybots & Mengubah bot yang telah dibuat \\
/setname & Mengubah nama bot \\
/setdescription & Mengubah informasi bot \\
/setuserpic & Mengubah foto profil bot \\
/setcommands & Mengkustom perintah-perintah diatas \\
/deletebot & Menghapus bot yang telah dibuat \\
/token & Menciptakan token otorisasi API \\
/revoke & Mencabut izin token otorisasi \\
/setinline & Mengganti mode inline \\
/setinlinegeo & Mengubah pesan ketika ada permintaan \\
& data lokasi \\
/setinlinefeed & Mengubah pengaturan balasan inline \\
back & \\
/setjoinsgroup & $\begin{array}{l}\text { Mengklasifikasikan beberapabot } \\
\text { kedalam 1 grup }\end{array}$ \\
/setprivacy & Mengubah mode privasi dalam grup \\
&
\end{tabular}

\section{Hasil dan Pembahasan}

Penelitian ini menghasilkan rancangan sistem IoT dalam bentuk prototype untuk monitoring temperatur dan pengendalian peralatan listrik yang berada diruang lingkup perumahan menggunakan aplikasi telegram dengan tahapan senagai berikut:

\section{Diagram Blok}

Diagram blok dari sistem Smart Home Berbasis IoT dengan Aplikasi Telegram adalah sebagai berikut: 


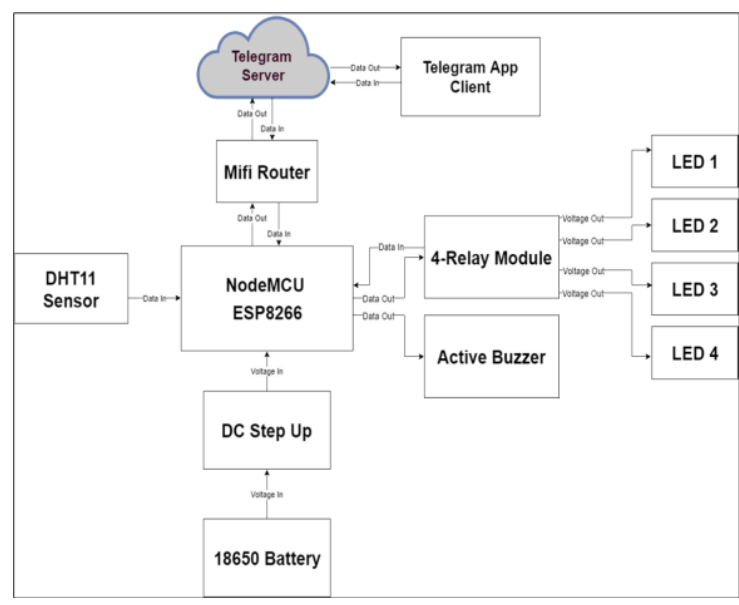

Gambar 13. Diagram blok

\section{Perakitan Rangkaian Elektronika}

Pada perakitan rangkaian elektronika sistem ini, diperlukan sebuah aplikasi yang mampu menggambarkan mock up dari komponen-komponen dan module elektronik yang diperlukan oleh sistem, aplikasi tersebut ada beberapa jenis, namun dalam penelitian ini menggunakan Aplikasi Fritzing karena sudah tersedia mock up setiap module yang akan digambarkan beserta alur wiring dari mikrokontroler [10].

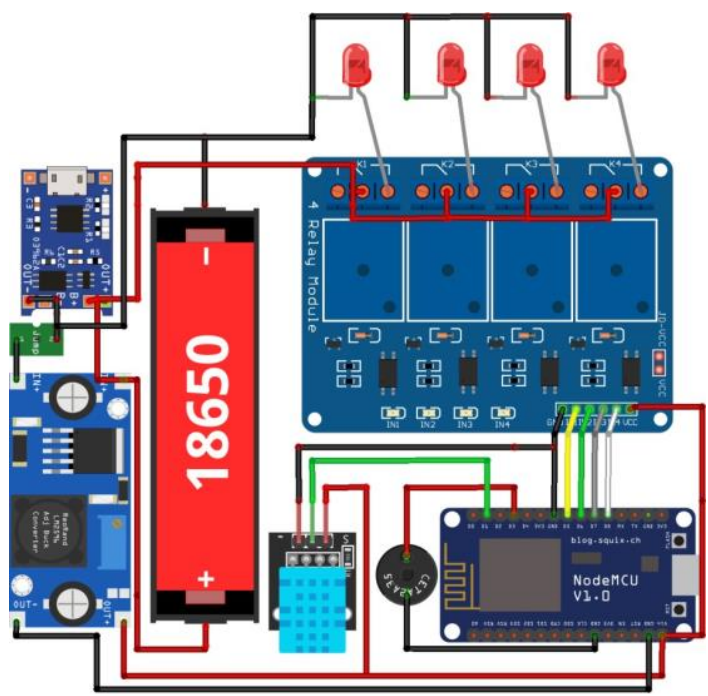

Gambar 14. Rangkaian elektronika sistem

Dari gambar rangkaian diatas dapat dijelaskan bahwa sistem inimenggunakan daya sebesar 5 volt yang didapatkan dari module DC Step $U p$ yang memiliki sumber daya cadangan ketika listrik padam berupa 1 buah baterai 186503.7 volt. Dalam rangkaian catu daya, diberikan jumper sebagai switch agar tidak terjadi arus feedback ke port USB komputer saat meng-upload program. Kemudian mikrokontroler NodeMCU terhubung dengan module-module dan komponen lainnya melalui 8 pin Digital sebagai jalur pengiriman data, VCC dan GND untuk mendapatkan tegangan. Terdapat sensor DHT11 yang terkoneksi melalui Pin D1, Active Buzzer yang terkoneksi melalui Pin D3, dan module relay 4channel yang terkoneksi melalui pin D5 untuk Relay 1
(LED 1), pin D6 untuk Relay 2 (LED 2), pin D7 untuk Relay 3 (LED 3), dan pin D8 untuk Relay 4 (LED 4) Diagram Alir Program

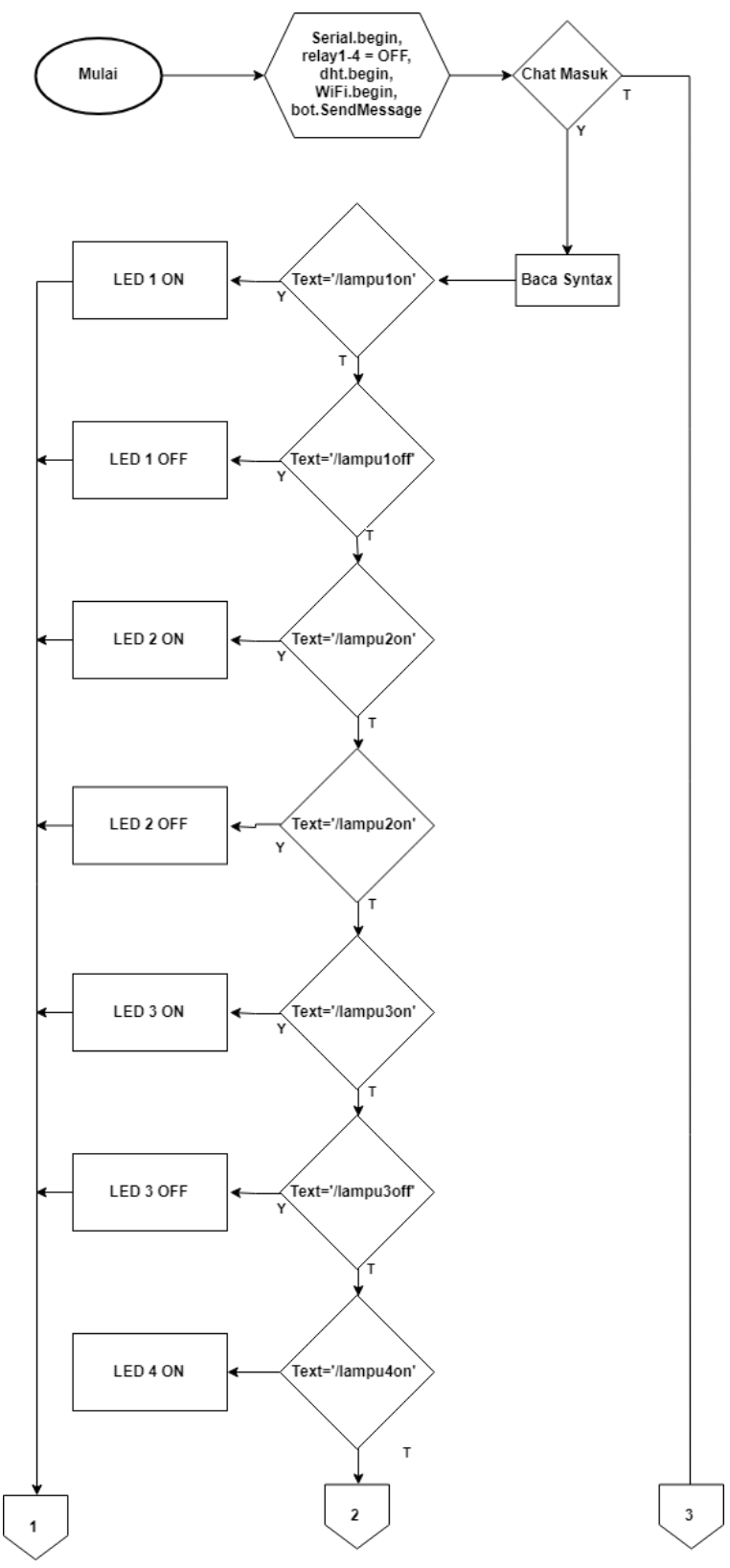




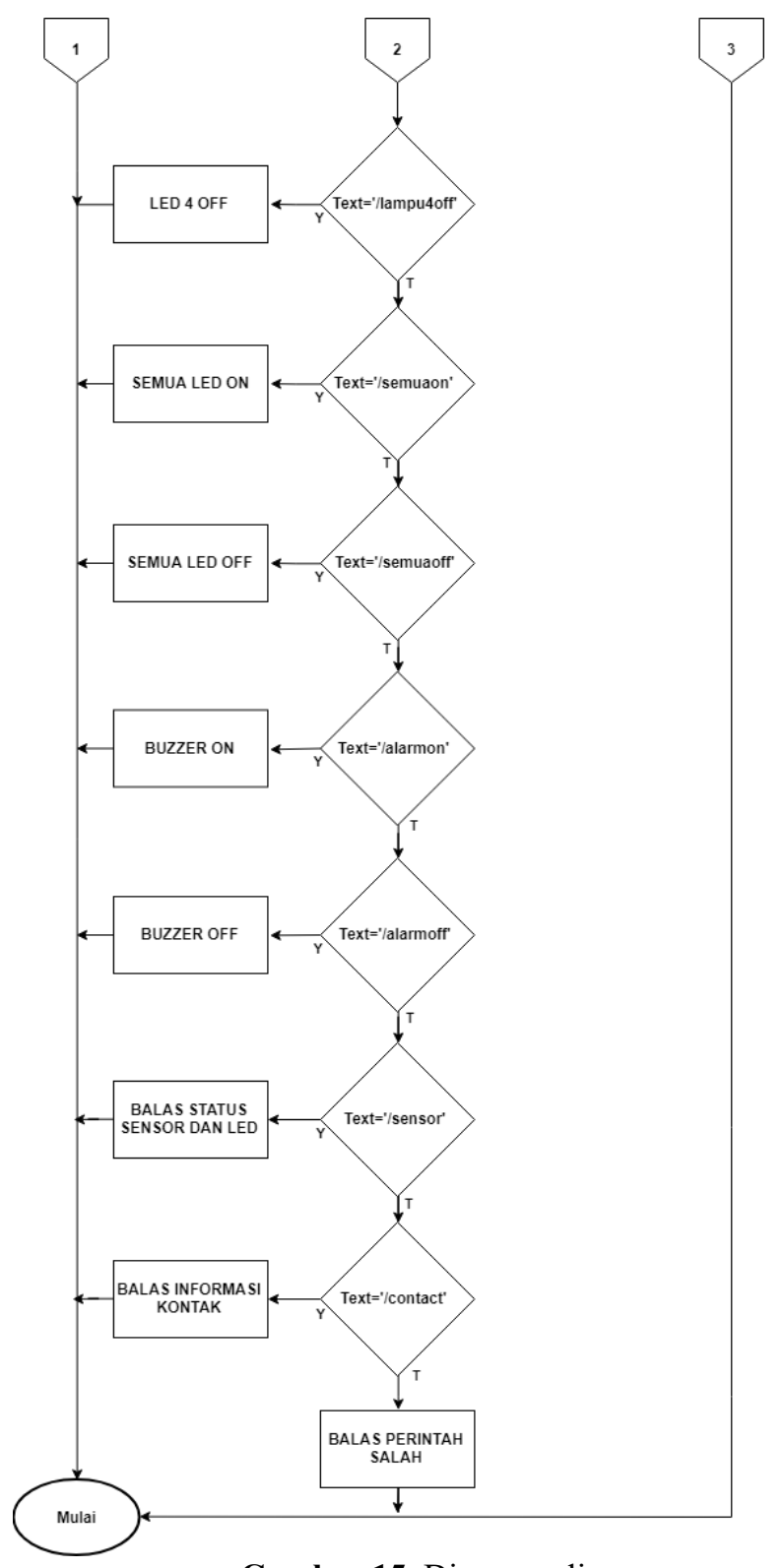

Gambar 15. Diagram alir

Dari diagram alir diatas, dapat dilihat bahwa tahap awal yang dijalankan ketika sistem dihidupkan adalah menginisialisasi komunikasi serial untuk debugging program, memulai koneksi ke relay, menjalankan sensor DHT11, mengkoneksikan ke Wi-Fi, dan kemudian mengirimkan pesan notifikasi ke pengguna bahwa sistem telah dijalankan. Selanjutnya sistem akan menunggupesan chat berupa perintah yang dikirim pengguna melalui aplikasi Telegram, jika perintah yang diterima sesuai dengan syntax maka akan diproses, adapun perintahperintah tersebut berguna untuk menyalakan module relay yang terhubung dengan 4 buah lampu LED yang dapat dinyalakan satu per satu dan sekaligus, menghidupkan alarm yang terhubung ke Active Buzzer dengan frekuensi tinggi, dan perintah terakhir yaitu untuk mendapatkan status dari setiap LED dan status Temperatur ruangan dari sensor DHT11. Jika perintah tidak dikenal maka sistem akan membalas bahwa perintah yang diberikan salah.

\section{Pembuatan Bot Telegram}

Dalam proses pembuatan Bot untuk sistem Smart Home, terdapat beberapa perintah yang tidak digunakan karena Bot yang diciptakan hanya untuk menerima perintah dan kemudian memanggil setiap fungsi yang ditentukan ketika perintah diterima. Berikut adalah tahapan-tahapan pembuatan Bot untuk Smart Home.

Tahap 1: Memulai komunikasi terhadap BotFather sebagai penyedia layanan Bot Telegram dengan perintah /start.

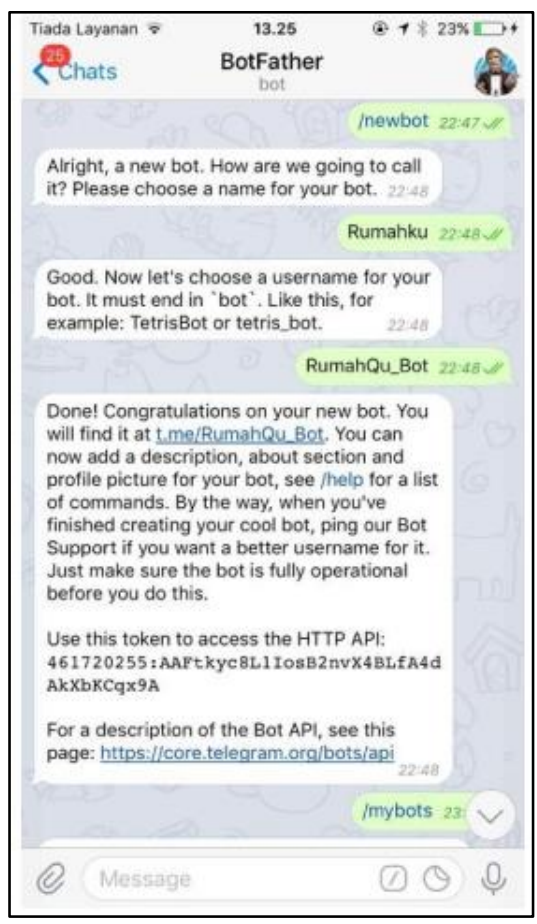

Gambar 16. Memberikan perintah pada bot

Tahap 2: Memberikan perintah /newbot untuk membuat Bot baru, BotFather aka nmemberikan kode API yang akan disematkan ke kode program mikrokontroler meminta data-data bot berupa nama bot dan nama akun dari bot yang akan dibuat

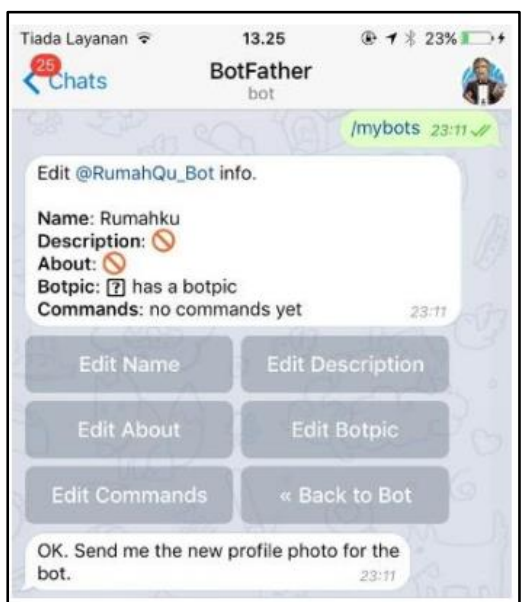

Gambar 17. Bot membalas beberapa tindakan terhadap bot 
Tahap 3: Memberikan perintah /mybots untuk memastikan apakah Bot sudah berhasil dibuat. BotFather akan memberikan opsi tindakan yang akan dilakukan terhadap bot seperti mengubah nama, deskripsi, foto profil bot, dan perintah-perintah tambahan yang akan diberikan.

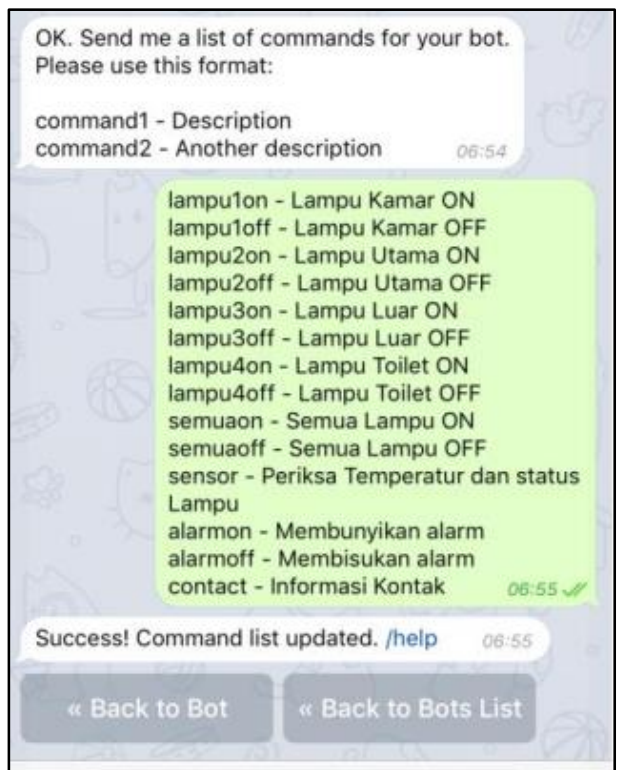

Gambar 18. Bot menerima daftar perintah yang dikirim

Tahap 4: Memberikan perintah /setcommand untuk membuat perintah-perintah yang akan tersedia untuk bot yang ditanam ke sistem melalui API.

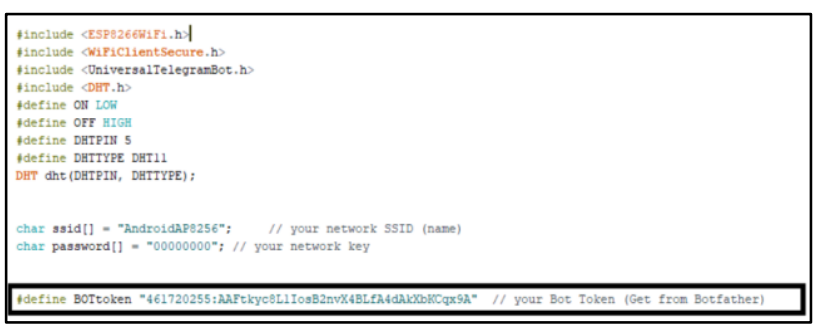

Gambar 19. Kode API disematkan ke dalam kode program

Bagian yang ditandai diatas merupakan token API untuk berkomunikasi dengan akun RumahQu_Bot melalui Telegram messenger.

\section{Pengujian Sistem}

Pada tahap ini dilakukan pengujian terhadap sistem yang telah dibuat dengan cara melakukan pengambilan data. Serangkaian pengujian yang dilakukan adalah sebagai berikut :

a. Pengujian pembacaan data pada status relay.

b. Pengujian pembacaan data pada sensor temperatur ruangan.

c. Pengujian komunikasi antara mikrokontroler dan aplikasi Telegram

d. Pengujian rangkaian sistem secara keseluruhan.

Pengujian secara keseluruhan bertujuan untuk memastikan apakah sistem yang telah dibuat dan seluruh module elektronika yang digunakan telah terintegrasi dan berfungsi dengan baik. Dalam tahap ini penulis menggantikan indikator dari status relay menggunakan LED yang tertanam pada module relay. Berikut pada gambar 4.5 alat dalam posisi relay atau Lampu Ruangan menyala dengan indikasi LED di module relay menyala yang diperjelas dengan petunjuk lingkaran berwarna merah, dan pada gambar 4.7 alat dalam posisi relay atau Lampu Ruangan padam dengan indikasi LED di module relay padam yang dapat diperjelas dengan petunjuk lingkaran berwarna merah.

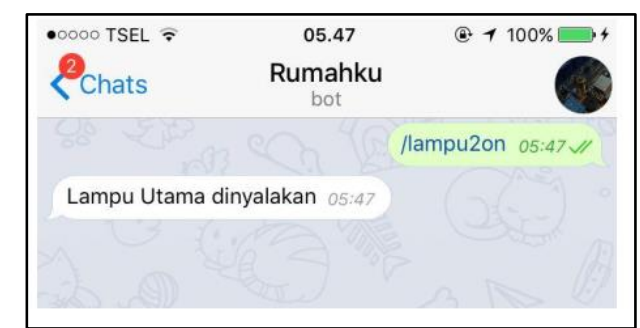

Gambar 20. Pengiriman perintah menyalakan lampu ruangan

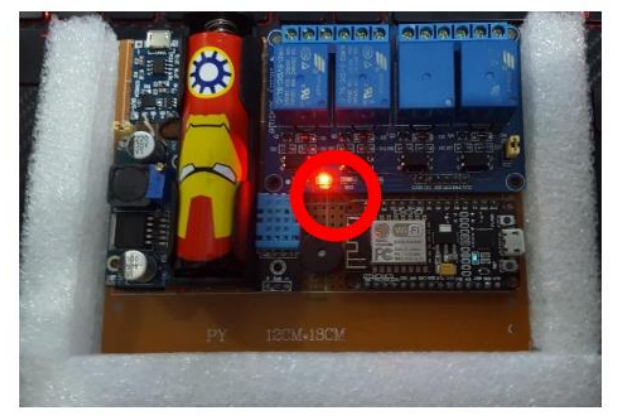

Gambar 21. Lampu ruangan menyala

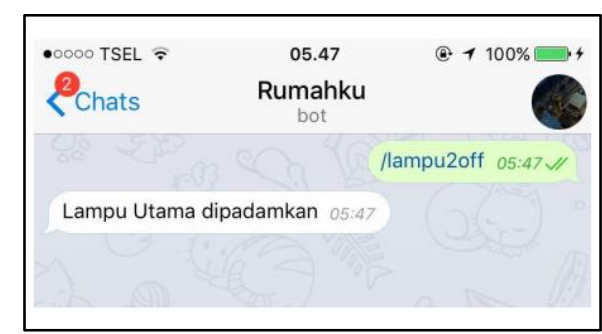

Gambar 22. Pengiriman perintah memadamkan lampu ruangan

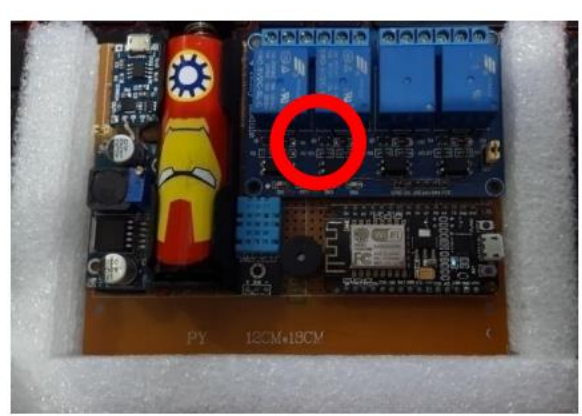

Gambar 23. Lampu ruangan padam 


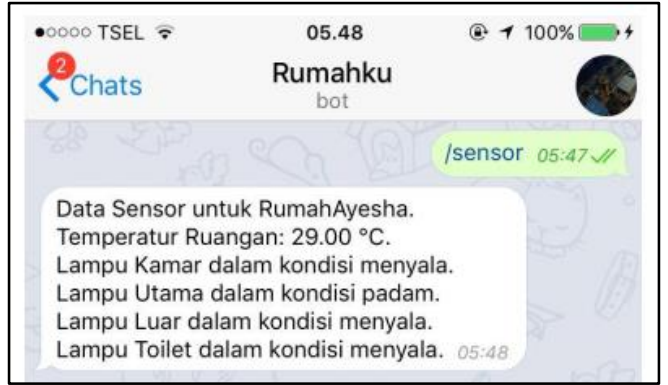

Gambar 24. Penerimaan notifikasi status lampu dan temperatur ruangan

Sistem kerja dari keseluruhan alat adalah berasal dari tegangan sebesar 5 volt DC yang didapat dari modul DC Step Up berdaya adaptor dengan cadangan berupa 1 buah baterai 18650, kemudian Buzzer akan mengeluarkan bunyi beep panjang menandakan sistem telah dijalankan, dan akan mengeluarkan bunyi beep 3 kali sebagai tanda sistem telah terkoneksi ke server Telegram. Setelah bunyi berhenti sistem akan mengirimkan notifikasi ke pemilik yang memberi tahu bahwa sistem telah online dan siap diberi perintah. Jika pemilik mengirimkan perintah yang tidak dikenal maka sistem secara otomatis membalas bahwa perintah tersebut tidak dikenal. Mekanisme tersebut digunakan untuk mencegah terjadinya pembajakan sistem Smart Home yang dapat membahayakan pemilik rumah, karena API Telegram bersifat open-source dan bot tidak diberikan sebuah fitur keamanan berupa password login. Dalam system ini penulis menambahkan mekanisme daya cadangan yang didapat dari baterai sehingga ketika listrik dalam rumah padam maka sistem akan tetap berjalan, karena itu sumber dari Wi-Fi yang digunakan harus berupa Mi-Fi (Mini Wi$\mathrm{Fi}$ ) yang koneksi internetnya tetap terhubung ketika listrik padam karena menggunakan daya dari baterai yang dicharge

\section{Kesimpulan dan Saran}

Sistem Smart Home untuk pengendalian sistem kelistrikan jarak jauh telah dibangun menggunakan mikrokontroler NodeMCU ESP8266 yang terkoneksi ke Wi-Fi untuk mendapatkan akses ke server Telegram. Hasil pengujian yang telah dilakukan menunjukkan bahwa sistem ini dapat bekerja dengan baik secara keseluruhan dimulai dari koneksi ke Wi-Fi, koneksi ke server Telegram, menerima perintah dan mengirim notifikasi. Sistem ini dapat terhubung ke server Telegram untuk dapat berinteraksi dengan pemilik dengan menggunakan kode API yang didapatkan dari BotFather yang disematkan kedalam kode program untuk diunggah ke mikrokontroler NodeMCU ESP8266.

Untuk pengembangan pada penelitian selanjutnya terdapat beberapa saran dalam pengembangan sistem yaitu: 1) Sebaiknya ditambahkan fitur keamanan pada sistem ketika pemilik hendak mengakses sistem seperti otorisasi password, 2) Penambahan sensor seperti sensor aliran air untuk mesin air, sensor pintu, kamera keamanan, dan sensor lain agar sistem ini dapat berfungsi sekaligus sebagai sistem keamanan.

\section{Daftar Pustaka}

[1] BPS, "Statistik Listrik 2012-2017," Badan Pusat Statistik, Katalog 6205005, 2018.

[2] S. Samsugi, Ardiansyah dan D. Kastutara, "Internet of Things (IoT): Sistem Kendali Jarak Jauh," in Prosiding Seminar Nasional XII Rekayasa Teknologi Industri dan Informasi, Yogyakarta, 2017.

[3] S. Samsugi, N. Neneng dan B. Aditama, "IoT: kendali dan otomatisasi si parmin (studi kasus peternak Desa Galih Lunik Lampung Selatan)," Prosiding Semnastek, vol. 1, no. 1, 2018.

[4] A. Nurkholis, A. Riyantomo dan M. Tafrikan, "Sistem pakar penyakit lambung menggunakan metode forward chaining," Majalah Ilmiah Momentum, vol. 13, no. 1, 2017.

[5] U. Asdea, A. Nurdin dan Asriyadi, "Perancangan Keamanan Rumah Berbasis IOT (Internet of Things)," in Seminar Nasional Inovasi dan Aplikasi Teknologi di Industri, 2019.

[6] A. Agus S, Zulkifli dan R. Gustriansyah, "Kendali Peralatan Listrik Dengan Sms Menggunakan Arduino Dan Gprs Shied," Jurnal Informatika Global, vol. 6, no. 1, pp. 33-37, 2015.

[7] D. E. Kurniawan, M. Iqbal, J. Friadi, R. I. Borman dan R. Rinaldi, "Smart Monitoring Temperature and Humidity of the Room," Journal of Physics: Conference Series, pp. 1-8, 2019.

[8] F. Arifiyanto, W. A. Syafei dan M. Somantri, "perancangan prototype web-based online smart home controlled by smartphone," Jurnal Ilmiah Teknik Elektro, vol. 2, no. 4, pp. 916-923, 2013.

[9] N. Y. D. Setyaningsih dan I. A. Rozaq, "prototype smart home kendali logika or berbasis arduino," Jurnal SIMETRIS, vol. 8, no. 2, pp. 559-562, 2017.

[10] A. Fatoni, D. D. Nugroho dan A. Irawan, "Rancang bangun alat pembelajaran microcontroller berbasis atmega 328 di universitas serang raya," PROSISKO: Jurnal Pengembangan Riset dan Observasi Sistem Komputer, vol. 2, no. 1, 2015. 